\title{
ELECTRONIC CONSTITUTION OF PARAMAGNETIC $3 d$ COMPLEXES AND POSITRONIUM CONVERSION RATE CONSTANTS
}

\author{
A.L. Fantola Lazzarini and E. Lazzarini \\ Dipartimento Ingegneria Nucleare, CeSNEF, Politecnico di Milano \\ Via Ponzio 34/3, 20133 Milano, Italy
}

\begin{abstract}
The rate constants, $k_{\mathrm{SE}}$, of ortho- into para-positronium spin cónversion reactions promoted by paramagnetic $3 d$ complexes may be correlated with their electronic constitution as it is described by the spin-orbit coupling and interelectronic repulsion parameters. The correlation is explained in terms of unpaired metal-electron delocalization towards the complex boundaries.
\end{abstract}

PACS numbers: 36.10.Dr, 61.66.Fn, 71.70.Ch, 78.40.Dw, 78.70.Bj

\section{Introduction}

Ortho-positronium may be converted into para-positronium (and vice versa) by interacting with paramagnetic compounds such as solvated electron $3 d$ and $4 f$ complexes, etc. The rate constants of ortho- into para-Ps conversion reactions, $k_{\mathrm{SE}}$, depend on the particular paramagnetic compound considered, e.g. the $k_{\mathrm{SE}}$ 's of ammoniated electron $\left(\mathrm{e}_{\mathrm{am}}^{-}\right), 3 d$ and $4 f$ aquo-ions are in the ratio 10:1:0.01 [1,2]. This finding suggested that the $k_{\mathrm{SE}}$ 's may depend on the spin density of unpaired electrons at the collision site between Ps and paramagnetic compound.

In order to support the hypothesis, a systematic investigation was carried out, in particular, the $k_{\mathrm{SE}}$ of the aquo-ion $\mathrm{Cr}$ (III) complexes listed in Table I and III were checked or measured for the first time.

\section{Experimental}

\subsection{Chemicals}

A few compounds were purchased, but the great part of them were prepared according to literature. 


\subsection{Reaction type}

As chemical entities, Ps atoms may promote several types of reactions, among them the spin-exchange (SE) and oxidation (Ox) reactions. It was ascertained by means of ACAR (Angular Correlation of Annihilation Radiation) or DBAR (Doppler Broadening of Annihilation Radiation) measurements that all the compounds studied promote only the o-Ps into $p$-Ps conversion reactions (henceforth simply called "conversion reactions"), but $\mathrm{Cu}_{\mathrm{aq}}^{2+}$ which may promote both $\mathrm{SE}$ and Ox reactions. Then its ACAR curves were analysed in order to obtain the $k_{\mathrm{SE}}$ and $k_{\mathrm{Ox}}$ contributions to the overall rate constant as described in Ref. [3]. The $\mathrm{Cu}_{\mathrm{aq}}^{2+}$ rate constant as shown in Table $\mathrm{I}$ is the $k_{\mathrm{SE}}$.

\subsection{Positron source}

About $0.5 \mathrm{MBq}(\approx 15 \mu \mathrm{Ci})$ of ${ }^{22} \mathrm{Na}$ from a carrier-free neutral solution supplied by Amersham were deposited between two identical kapton foils (1.065 $\mathrm{mg} \mathrm{cm}^{-2}$ ) which were sealed together with a cyanoacrilate adhesive. The source was suspended in vials containing the reactant solution. $\mathrm{O}_{2}$ was removed from the vials by bubbling $\mathrm{N}_{2}$. During the measurements the temperature was kept constant within $0.1 \mathrm{~K}$.

\subsection{Annihilation spectra}

Apparatuses and methods have been already described [4]. Shortly, the $k_{\mathrm{SE}}$ values were obtained from the decay constant $\lambda$ of the component of the time spectra with the longest meanlife as described in Refs. $[2 ; 4]$.

\subsection{Kinetics of the $S E$ conversion reactions}

The $k_{\text {SE }}$ were measured at different temperatures and the results were analysed as described in Ref. [4] to ascertain whether the reactions were diffusion controlled. Since this was confirmed and the rate constants of diffusion controlled reactions depend on the viscosity coefficient of the reaction medium and therefore on the reactant concentrations, $\lambda$ and therefore $k_{\mathrm{SE}}$ values are normalised to the viscosity coefficient of pure water as described in Ref. [2]. The viscosity coefficients of the reaction media were measured by means of a KPG Ubbelohde Viscosimeter (B.S. 188; ASTM 2515; Jenaer Glasswerk Schott and Gen; Mainz).

\section{Results}

Only the rate constants at $298 \mathrm{~K}$ are reported here, since they are enough for supporting our working hypothesis. The data concerning the aquo-ions are shown in Table I from which it may be noted: (a) that the $k_{\mathrm{SE}}$ 's do not depend on the unpaired electron number, i.e. on the spin-only magnetic moment, $\mu_{\mathrm{SO}}$; and (b) that on the bases of the $k_{\mathrm{SE}}$ values the ions may be divided into two groups, the $k_{\mathrm{SE}}$ 's of the first group, formed by $\mathrm{Mn}_{\mathrm{aq}}^{2+}$ and $\mathrm{Cr}_{\mathrm{aq}}^{3+}$ ions, are $\approx 1 \mathrm{M}^{-1} \mathrm{~ns}^{-1}$, whereas those of the second group, formed by $\mathrm{Fe}_{\mathrm{aq}}^{2+}, \mathrm{Co}_{\mathrm{aq}}^{2+}, \mathrm{Ni}_{\mathrm{aq}}^{2+}$, and $\mathrm{Cu}_{\mathrm{aq}}^{2+}$ ions are about 
TABLE I

$k_{\mathrm{SE}}\left[\mathrm{M}^{-1} \mathrm{~ns}^{-1}\right]$ of listed aquo-ions. Spin-only, $\mu_{\mathrm{So}}$, and experimental, $\mu_{\mathrm{eff}}$, magnetic moments in Bohr's magneton [BM] are also shown $\left(\mu_{\text {eff }}\right.$ and $\mu_{\mathrm{SO}}$ from Ref. [5]).

\begin{tabular}{c|c|c|c|c|c|l}
\hline \hline Ion & $\mathrm{Cr}_{\mathrm{aq}}^{3+}$ & $\mathrm{Mn}_{\mathrm{aq}}^{2+}$ & $\mathrm{Fe}_{\mathrm{aq}}^{2+}$ & $\mathrm{Co}_{\mathrm{aq}}^{2+}$ & $\mathrm{Ni}_{\mathrm{aq}}^{2+}$ & $\mathrm{Cu}_{\mathrm{aq}}^{2+}$ \\
\hline$k_{\mathrm{SE}}$ & $1.01 \pm 0.9$ & $1.09 \pm 0.05$ & $2.26 \pm 0.02$ & $2.21 \pm 0.07$ & $2.58 \pm 0.03$ & $\approx 1.6$ \\
$\mu_{\mathrm{SO}}$ & 3.87 & 5.92 & 4.90 & 3.87 & 2.83 & 1.73 \\
$\mu_{\mathrm{eff}}$ & 3.8 & 5.9 & 5.3 & 5.1 & 3.2 & $1.9-2.0$
\end{tabular}

twice bigger. Looking for an explanation one may observe that only for the ions of the second group $\mu_{\text {eff }}$ is bigger than $\mu_{\text {So }}$, i.e. spin-orbit coupling occurs only for the ions of the second group. This trend can be easily justified if one supposes that $k_{\mathrm{SE}}$ increases as the density of unpaired metal electrons increases at the collision site between complex and Ps atom (i.e. at the complex boundaries and that the electron delocalization from atom is larger when spin-orbit coupling occurs. Measurements in progress suggest that the same conclusion is also true for the complexes formed by the same metal ions with $\mathrm{H}_{4}$ EDTA (ethylenediaminetetraacetic acid).

TABLE II

$\beta$ ratios of $\mathrm{Cr}$ (III) complexes formed with sets of six equal mono- or three equal bidentate ligands. The nephelauxetic effect increases as $\beta$ decreases [8] (ox ${ }^{2-}=$ oxalate, en $=$ ethylenediamine).

\begin{tabular}{c|c|c|c|c|c|c|c|c}
\hline \hline Ligand & $6 \mathrm{H}_{2} \mathrm{O}$ & 6 6rea & $6 \mathrm{NH}_{3}$ & $3 \mathrm{ox}^{2-}$ & $3 \mathrm{en}$ & $6 \mathrm{NCS}^{-}$ & $6 \mathrm{CN}^{-}$ & $6 \mathrm{Cl}^{-}$ \\
\hline$\beta$ & 0.79 & 0.72 & 0.71 & 0.68 & 0.67 & 0.62 & 0.58 & 0.56
\end{tabular}

In order to discuss the data of Table II some basic chemistry must be recalled [6]. The fivefold degenerate $3 d$ orbitals of $\mathrm{Cr}$ (III) gaseous ion in an octahedral arrow of six equal ligands (e.g. six $\mathrm{CNS}^{-}$or $\mathrm{CN}^{-}$ions or six $\mathrm{H}_{2} \mathrm{O}$ or $\mathrm{NH}_{3}$ molecules) are split into a lower triplet, $t_{2 \mathrm{~g}}$, and an upper doublet, $e_{\mathrm{g}}$, the separation between them, usually called $10 D q$, depends on the ligands which may be arranged in a series of increasing capability to cause $3 d$ orbital splitting [6]. The series is in part

$$
\begin{aligned}
& 6 \mathrm{Cl}^{-}<3 \mathrm{C}_{2} \mathrm{O}_{4}^{2-} \text { (or } 3 \mathrm{ox}^{2-} \text { ) } \\
& \quad \approx 6 \mathrm{H}_{2} \mathrm{O}<6 \mathrm{NCS}^{-}<6 \mathrm{NH}_{3}<3\left(\mathrm{CH}_{2} \mathrm{NH}_{2}\right)_{2}<6 \mathrm{CN}^{-} .
\end{aligned}
$$

Since absorption transitions may occur between triplet and doublet states, the $10 D q$ separation value can be measured by UV absorption spectroscopy. For octahedral $\mathrm{Cr}$ (III) complexes the absorption spectra consist of three transitions whose energies $\bar{\nu}\left[\mathrm{cm}^{-1}\right]$ are given by Eqs. (1a) and (1b) [7]:

$$
\bar{\nu}_{1}=10 D q
$$




$$
\bar{\nu}_{2,3}=7.5 B+15 D q \pm 0.5\left\{225 B^{2}+100(D q)^{2}-180 B D q\right\}^{1 / 2}
$$

where $B$ is the Racah interelectronic repulsion parameter. The $B$ values of complexes are smaller than the $B_{0}$ value of the free gaseous ion (i.e. $B / B_{0}=\beta<1$ ), this means that the overlapping of metal and ligand orbitals provides a path by which metal electrons can, and do, escape to a certain extent from $3 d$-ion towards ligands and molecule boundaries. The effect has been named "nephelauxetic" (expanding cloud, from Greek) [6]. Summing up: $\beta$ values, which can be derived by means of spectrochemical measurements, decrease as the electron delocalization from metal atom towards ligands increases.

The ligands can be arranged in a series of increasing capability to cause $d$ cloud expansion, that is, of decreasing $\beta$ values [8]. The series for $\operatorname{Cr}(\mathrm{III})$ is shown in part in Table II. For complexes formed with sets of mixed ligands an "average environment rule" [9] applies, i.e. the $\beta$ value of these complexes are given by Eq. (2):

$$
\beta=1-h \sum n_{i} \beta_{i} / r_{J},
$$

where $\beta_{i}$ is the $B / B_{0}$ ratio for a set of six equal mono- or three equal bidentate ligands; $n_{i}$ is the number of $i$-th ligand in the complex; $r_{J}$ is 6 for mono- and 3 for bidentate ligands; $h$ depends on $3 d$ ion, in particular for $\mathrm{Cr}$ (III) it is $h=0.21$.

Since the rate constants $k_{\mathrm{SE}}$ of $o$-Ps to $p$-Ps conversion reactions should increase as the spin density of unpaired electrons at complex boundaries increases, we argued that the $k_{\mathrm{SE}}$ and $\beta$ values of $\mathrm{Cr}$ (III) complexes should be correlated.

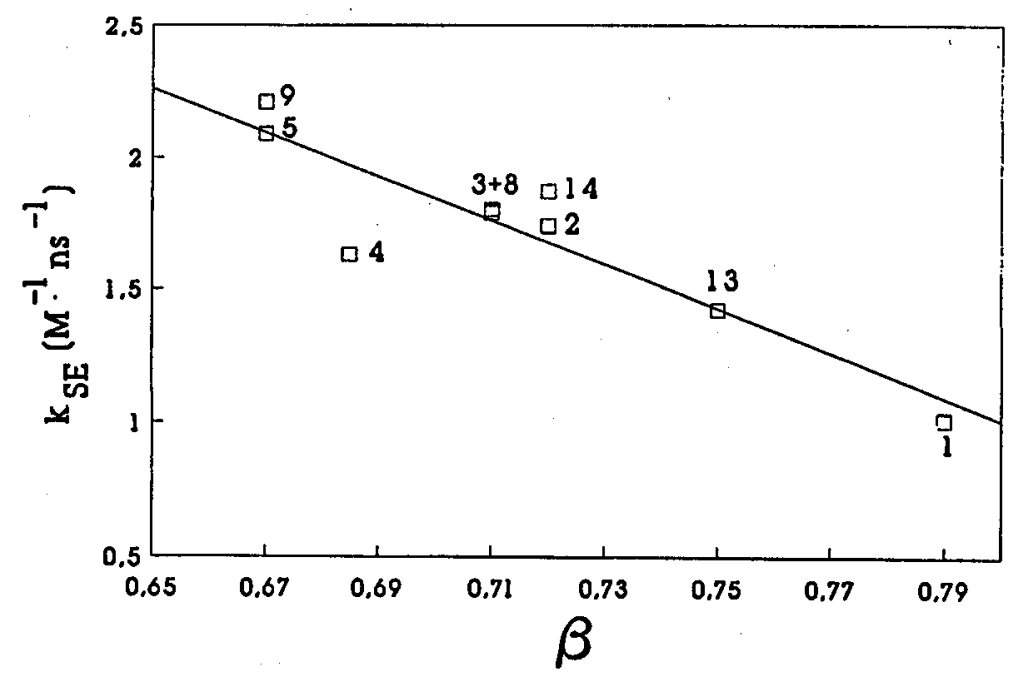

Fig. 1. The $k_{\mathrm{SE}}$ values of complexes $1-5$ and $8-11$ of Table III plotted against their $\beta$ values. See Table III for point numeration.

Actually the data of Table III suggest that $k_{\mathrm{SE}}$ increases as $\beta$ ratio decreases (items 1-7). The hypothesised relationship emerges, perhaps more clearly, 
TABLE III

$k_{\mathrm{SE}}\left(\mathrm{M}^{-1} \mathrm{~ns}^{-1}\right)$ at $298 \mathrm{~K}$ of the o-Ps to $p$-Ps $\mathrm{SE}$ reactions promoted by the following $\mathrm{Cr}$ (III) complexes. $\bar{k}_{\mathrm{SE}}$ are the backcalculated rate constants using the "average environmental rule" (see the text).

\begin{tabular}{|c|c|c|c|c|c|}
\hline Item ${ }^{\bullet}$ & Complex & $k_{\mathrm{SE}}$ & $\beta$ & $\bar{k}_{\mathrm{SE}}$ & $100 \frac{k_{S E}-k_{S E}}{k_{s S}}$ \\
\hline 1 & $\mathrm{Cr}_{\mathrm{aq}}^{3+} \mathrm{K}$-alum & $1.01 \pm 0.09$ & $0.79^{*}$ & 0.99 & +2 \\
\hline 2 & {$\left[\mathrm{Cr}(\text { urea })_{6}\right] \mathrm{Cl}_{3}$} & $1.74 \pm 0.06$ & $0.72^{*}$ & 1.74 & $n s^{\circ}$ \\
\hline 3 & {$\left[\mathrm{Cr}\left(\mathrm{NH}_{3}\right)_{6}\right] \mathrm{Cl}_{3}$} & $1.79 \pm 0.03$ & $0.71^{*}$ & 1.80 & - \\
\hline 4 & $\mathrm{~K}_{3}\left[\mathrm{Cr} \quad \mathrm{ox}_{3}\right]$ & $1.63 \pm 0.09$ & $0.68^{*}$ & 1.83 & -12 \\
\hline 5 & {$\left[\begin{array}{lll}\mathrm{Cr} & \left.\mathrm{en}_{3}\right] \mathrm{Cl}_{3}\end{array}\right.$} & $2.09 \pm 0.06$ & $0.67^{*}$ & 2.19 & -5 \\
\hline 6 & $\mathrm{~K}_{3}\left[\mathrm{Cr}(\mathrm{CNS})_{6}\right]$ & $8.15 \pm 0.17$ & $0.62^{*}$ & 7.97 & +2 \\
\hline 7 & $\mathrm{~K}_{3}\left[\mathrm{Cr}(\mathrm{CN})_{6}\right]$ & $6.85 \pm 0.12$ & $0.58^{*}$ & 6.85 & $\mathrm{~ns}^{\circ}$ \\
\hline 8 & {$\left[\mathrm{Cren}_{2}\left(\mathrm{H}_{2} \mathrm{O}\right)_{2}\right]_{2}\left(\mathrm{~S}_{2} \mathrm{O}_{3}\right)_{3}$} & $1.80 \pm 0.03$ & $0.71^{\Delta}$ & 1.79 & - \\
\hline 9 & {$\left[\mathrm{Cren}_{2} \mathrm{ox}\right] \mathrm{Cl}$} & $2.21 \pm 0.07$ & $0.67^{\Delta}$ & 2.07 & +6 \\
\hline 10 & {$\left[\mathrm{Cren}_{2}(\mathrm{CNS})_{2}\right] \mathrm{CNS}$} & $4.96 \pm 0.13$ & $0.65^{\Delta}$ & 4.12 & +17 \\
\hline 11 & {$\left[\mathrm{Cr}\left(\mathrm{H}_{2} \mathrm{O}\right)_{5} \mathrm{Cl}\right] \mathrm{Cl}_{2}$} & $2.63 \pm 0.15$ & $0.75^{\Delta}$ & 2.64 & - \\
\hline 12 & $\mathrm{NH}_{4}\left[\mathrm{Cr}\left(\mathrm{NH}_{3}\right)_{2}(\mathrm{CNS})_{4}\right]$ & $5.07 \pm 0.18$ & $0.75^{\Delta}$ & 5.94 & -17 \\
\hline 13 & $\mathrm{~K}\left[\mathrm{CrEDTA} \mathrm{H}_{2} \mathrm{O}\right]$ & $1.42 \pm 0.02$ & 0.75 & 1.39 & +2 \\
\hline 14 & {$\left[\mathrm{Cr}\left(\mathrm{NH}_{3}\right)_{5} \mathrm{H}_{2} \mathrm{O}\right]\left(\mathrm{NO}_{3}\right)$} & $1.87 \pm 0.03$ & $0.72^{\Delta}$ & 1.66 & +11 \\
\hline
\end{tabular}

- ox $^{2-}=$ oxalate, $\mathrm{H}_{4}(\mathrm{EDTA})=$ ethylenediaminetetraacetic acid,

en $=$ ethylenediamine.

* Experimental results,

$\Delta$ Calculated by means of the "average environment rule" (Eq. (2)).

- Not significant, since the ligands appear in only one complex.

by plotting the $k_{\mathrm{SE}}$ 's of the following three series of complexes vs. their $\beta$ values: $\left[\mathrm{Cr}\left(\mathrm{NH}_{3}\right)_{6-n}(\mathrm{CNS})_{n}\right]^{+(3-n)}(n=0,4,6) ;\left[\mathrm{Cren}_{3-n}(\mathrm{CNS})_{2 n}\right]^{+(3-n)}(n=0,1,3)$; [Cren $\left._{n}\left(\mathrm{H}_{2} \mathrm{O}\right)_{6-2 n}\right]^{3+}(n=0,1,2,3)\left([\mathrm{CrEDTA}]^{-}\right.$was considered equivalent to [Cren $\left.\left.\left(\mathrm{H}_{2} \mathrm{O}\right)_{4}\right]\right)$. Indeed, the $k_{\mathrm{SE}}$ values of each series are linearly dependent on $n$ and therefore on $\beta$.

Thus an "a verage environment rule", similar to that valid for $\beta$ ratios, should also be valid for $k_{\mathrm{SE}}$ values. According to this hypothesis and by applying the method of maximum likelihood to the $k_{\mathrm{SE}}$ 's of Table III, the contribution of each ligand used was deduced. The backcalculated $\bar{k}_{\mathrm{SE}}$ values are also shown in Table III. The agreement between $k_{\mathrm{SE}}$ and $\bar{k}_{\mathrm{SE}}$ values is rather satisfactory.

Finally the $k_{\mathrm{SE}}$ 's may also depend on other parameters which can cause electron delocalization, e.g. $\pi$ bonding (as for $\mathrm{Cl}^{-}$and $\mathrm{CN}^{-}$ligands) or appropriate resonant structures (as for $\mathrm{NCS}^{-}$). When such factors do not play a role, the $k_{\mathrm{SE}}$ are linearly dependent on $\beta$ as can be verified by plotting the data of complexes 1-5 and 8-11 of Table III against the corresponding $\beta$ values (Fig. 1). 
Thus one may wonder whether the time is ripe for Ps to be used as a probe for studying the chemical constitution of complexes.

\section{References}

[1] A.L. Fantola Lazzarini, E. Lazzarini, Acta Univ. Wratislav. Mat. Fiz. Astron. 1204, 181 (1989).

[2] A.L. Fantola Lazzarini, E. Lazzarini, Struct. Chem. 2, 409 (1991).

[3] F. De Natale, A. Dupasquier, A.L. Fantola Lazzarini, E. Lazzarini, A. Rolando, Mater. Sci. Forum 105-110, 1537 (1992).

[4] A.L. Fantola Lazzarini, E. Lazzarini, J. Phys. B, At. Mol. Opt. 22, 541 (1989).

[5] J.A.A. Katelaar, Chemical Constitution, Elsevier, London 1970, p. 182.

[6] F.A. Cotton, G. Wilkinson, Advanced Inorganic Chemistry, 1st ed., Interscience, New York 1962, p. 560.

[7] Yu-Sheng Dou, J. Chem. Educ. 67, 134 (1990).

[8] E.S. Schäffer, C.K. Jorgensen, J. Inorg. Nucl. Chem. 8, 143 (1958).

[9] E.N. Figgis, Introduction to Ligand Field, Interscience, London 1971, p. 242. 